\title{
JURISPRUDENCIA AMBIENTAL EN CASTILLA LA MANCHA (SEGUNDO SEMESTRE 2018)
}

\author{
Nuria Maria Garrido Cuenca \\ Catedrática Derecho Administrativo \\ Universidad Castilla y la Mancha
}


Sumario: 1. Índice: a vueltas con el ATC de Villar de Cañas. 2. Autorización ambiental integrada y publicación previa de la declaración de impacto ambiental. La polémica sobre las macrogranjas porcinas en el ámbito autonómico. 3. Jurisprudencia en materia sancionadora. 4. Jurisprudencia constitucional y fracking: la constitucionalidad de la ley castellano-manchega.

\section{A VUELTAS CON EL ATC DE VILLAR DE CAÑAS. LA ANULACIÓN DE LAS ACTUACIONES DE AMPLIACIÓN DEL ESPACIO PROTEGIDO, MODIFICACIÓN DEL PORN Y ZEPA DE LA LAGUNA DEL HITO Y EL NUEVO ESCENARIO DE LA POLITICA ENERGETICA ESTATAL}

En el episodio jurisprudencial sobre la ubicación del ATC, sobre el que venimos dando cuenta en estas crónicas, han acontecido en el periodo que abarcan estas crónicas varios hechos que pueden cambiar el resultado final del ya largo conflicto jurídico, judicial, político y social que ha generado. En este momento toca dar cuenta de la STSJCM , (Sala de lo Contencioso-Administrativo, Sección 1a) Sentencia número 209/2018 de 30 julio (JURl2018|274901), que anula el Acuerdo de 28 de julio de 2015, del Consejo de Gobierno de Castilla La Mancha por el que se inicia el procedimiento para la ampliación del Espacio Protegido Red Natura 2000 Laguna del Hito y de la modificación del Plan de Ordenación de los Recursos Naturales de la Reserva Natural de la Laguna Hito, así como el Decreto 57/2016 de 4 de octubre de 2016 por el que se amplía la Zona de Especial Protección para las Aves ( ZEPA) Laguna de El Hito y se realiza la propuesta a la Comisión Europea para su declaración como Lugar de Importancia Comunitaria.

No obstante, aunque en muy resumidos términos, nuestro tribunal ha entendido que primaba la gestión de los residuos nucleares sobre la protección de la zona, hay que dudar en estos momentos de la trascendencia de esta decisión judicial. Y ello pues, la nueva ministra de Transición Energética ha paralizado los trámites administrativos todavía pendientes. Así, el 2 de julio se envió una carta al Consejo de Seguridad Nuclear (CSN) indicándole que suspendiera la emisión de su informe en relación con la autorización de construcción del ATC. Sin embargo, este fallo no supone en absoluto la luz verde para el ATC, pues está frenado por la no aprobación del Plan de Ordenación Municipal y por la suspensión del proceso de licencia en el consejo de Seguridad Nuclear. Por tanto, todavía no existe decisión sobre la "autorización previa o de emplazamiento", cuyo 
expediente completo tiene la ministra encima de su mesa y que todo parece indicar que será denegado.

El nuevo Gobierno ha anunciado que se abre un proceso de planificación sobre el modelo energético, en el que definirá el encaje de la energía nuclear y se planteará el posible proceso de desmantelamiento de las centrales. Una vez definido este proceso, será el momento de discutir el modelo de gestión de los residuos nucleares que deberá ser participado y democrático, fundamentalmente. Aunque es cierto que, frente al modelo de cementerio nuclear, parece abrirse paso a la alternativa, ampliamente extendida en la experiencia internacional de los almacenes de contenedores en seco, también llamados almacenes temporales individualizados (ATI). Por ejemplo, EE UU o Canadá nunca han contemplado un ATC como una infraestructura necesaria para almacenar temporalmente sus residuos radioactivos o de uranio. $Y$, de hecho, nuestro país ha empezado también a invertir en este modelo, en concreto en Trillo, Zorita y Ascó con 57 contenedores ya fabricados de doble uso (a 31 de diciembre de 2017 según el CSN). Por tanto, es todavía una incógnita que deberá despejarse por el nuevo ejecutivo nacional.

A pesar de este nuevo escenario, toca en estas crónicas hacer balance de la Sentencia de nuestro Tribunal Superior que, a mi juicio, se ha dictado más en suposiciones que en hechos reales fehacientemente comprobados. Como demuestra por otro lado la multitud de explícitos interrogantes que la propia decisión contiene sobre las intenciones del Gobierno regional que, además, me parece importante resaltarlo, no es el mismo que en su momento decidió la ubicación del ATC en discusión. Creo que nuestro Tribunal ha hecho una interpretación extensiva de las competencias estatales exclusivas en materia de ordenación económica y política energética, haciéndolas absolutamente prevalentes sobre las también competencias autonómicas en materia de protección ambiental de nuestra administración regional. Aplicación además de la muy excepcional cláusula de prevalencia del derecho estatal que no termina de argumentarse con el rigor que requeriría. Pasemos, por tanto, al análisis de los argumentos principales de la decisión judicial.

El recurso tiene como objeto dos resoluciones: 
-el Acuerdo de 28 de julio de 2015, del Consejo de Gobierno de Castilla La Mancha por el que se inicia el procedimiento para la ampliación del Espacio Protegido Red Natura 2000, Laguna del Hito y de la modificación del Plan de Ordenación de los Recursos Naturales de la Reserva Natural de la Laguna Hito y se establece un periodo de información y participación pública (Diario Oficial de Castilla La Mancha, 29 de julio de 2015),

- el Decreto 57/2016 de 4 de octubre de 2016 por el que se amplía la Zona de Especial Protección para las Aves ( ZEPA ) Laguna de El Hito y se realiza la propuesta a la Comisión Europea para su declaración como Lugar de Importancia Comunitaria (LIC) (Diario Oficial de Castilla La Mancha, 11 de octubre de 2016). Este declara finalmente ZEPA los terrenos que constituyen la ampliación, con la consecuente consideración de espacio protegido (art. 41 de la Ley 42/2007 de 13 de diciembre, de Patrimonio Natural y de la Biodiversidad), así como zona sensible (art.54 de la Ley 9/1999 de 26 de mayo, de Conservación de la Naturaleza) .

Como bien comienza aclarando la sentencia, el proceso no se centra en dirimir el impacto ambiental del Almacén Nuclear previsto en el municipio de Villar de Cañas, ni las consecuencias derivadas del establecimiento de dicha infraestructura en los valores naturales y ambientales de su entorno. Sobre la pertinencia o no de la ubicación del Almacenamiento, o la conveniencia de los almacenes temporales centralizados frente a los individualizados, ya han sido objeto de debate judicial (del que se ha dado cuenta en Crónicas anteriores). En fin, tampoco cree el Tribunal que proceda pronunciamiento sobre las alternativas a la gestión de combustible gastado o residuos de alta actividad del Almacén, ni la suficiencia de recursos hidrológicos para el desarrollo del proyecto.

En definitiva, esta sentencia se debe limitar a discernir si el espacio previsto para albergar la ampliación de la ZEPA es o no conforme a derecho, en la medida en que el territorio incluido en dicha ampliación, se incrementa desde una superficie cercana a las 1.0000 hectáreas hasta las 23.598,06 has. Aunque, comienza ya señalando el Tribunal, que en este asunto "Obviamente, no se puede ignorar que parte de dicha ampliación, coincide con aquella superficie en la que se encuentra proyectado el Almacén Nuclear, con las consecuencias legales que luego se analizarán". 
La metodología seguida por el Tribunal para responder a las cuestiones planteadas por las partes se explica del siguiente modo: conflicto de competencias entre el Estado y la Comunidad Autónoma, defectos formales observados en la tramitación del Acuerdo y del Decreto, (básicamente información pública y memoria económica) y por último, cuestiones de fondo en las que se discute el valor ecológico y paisajístico de la zona ampliada, analizando el conjunto de especies vegetales y animales que habitan en el lugar. Una serie de materias que el propio tribunal escalona, "de modo que la estimación del recurso por el primer motivo, excluiría la necesidad de pronunciamiento respecto del resto". Y esto es lo que sucede realmente.

Así, la sentencia entiende que debe contraponer la dimensión estratégica que supone para el Estado la producción energética, entre la que se incluye la gestión y emplazamiento de los residuos nucleares, junto a la seguridad de personas, sociedad y naturaleza; con el ejercicio de aquellas otras competencias medioambientales asumidas por parte de la Comunidad Autónoma, en la que se incardina la protección de su biota. Lo que evidencia la existencia de una concurrencia de competencias, pues su ejercicio por parte de ambas administraciones públicas tiene la misma proyección territorial. Es decir, la ampliación de la ZEPA Laguna del Hito y la modificación del Plan de Ordenación de la Reserva Natural afecta directamente a aquellos territorios en los que se ha previsto la ubicación de un almacén nuclear por parte del Estado.

Por tanto, en los casos de concurrencia de competencias en el mismo espacio físico se deberá optar para su solución, en primer lugar, por la utilización de las diversas técnicas de coordinación, colaboración y cooperación interadministrativas, basadas en la voluntariedad y el mutuo acuerdo. Pues, de acuerdo a la doctrina constitucional, "la atribución de una competencia sobre un ámbito físico determinado, no impide necesariamente que se ejerzan otras competencias en el mismo espacio, siempre que tengan distinto objeto y no interfieran entre sí ( SSTC 82/2012 de 18 de abril de 2012”. Sin embargo, esta técnica le parece insuficiente al Tribunal para este caso, al entender que la propuesta de Lugar de Importancia Comunitaria que realiza la Junta de Comunidades en 2015 obliga a la Comunidad Autónoma a adoptar "medidas de protección adecuadas " y en concreto impide realizar actos que supongan una 
transformación sensible de la realidad física y biológica, mientras se tramita el plan de Ordenación de los Recursos Naturales o se desarrolla la tramitación del procedimiento para declarar un espacio natural protegido. Ello afecta de manera directa a los intereses del Estado, pues la ampliación del territorio inicial de la ZEPA de la Laguna de El Hito, incluye el espacio, donde está proyectada la instalación del Almacén Temporal Centralizado y su Centro Tecnológico Asociado.

Descartada esta vía de solución, el Tribunal hará aplicación preferente del principio de prevalencia como técnica subsidiaria de solución de concurrencia competencial. Negando además que pudiéramos estar ante un conflicto futuro de competencias (como señalara el Letrado de Ecologistas en Acción). De hecho, no se puede ignorar que el establecimiento de este régimen preventivo de protección de los artículos 30, 32.4 y 56 de la Ley 9/1999 de Conservación de la Naturaleza de Castilla La Mancha propició en las presentes actuaciones, la adopción de la medida cautelar de suspensión a través de la Sentencia 2651/2016 de 16 de diciembre del Tribunal Supremo, por la que revoca los Autos que esta Sala había dictado en fechas 22 de diciembre de 2015 y 9 de febrero de 2016.

$\mathrm{Y}$, por tanto, y trascribimos literalmente: "Llegados a este punto, debemos cuestionarnos ¿ha procedido la Junta de Comunidades a ampliar el territorio de la Laguna de El Hito, al albur, de la competencia en materia de medio ambiente que le corresponde y, dentro de sus límites o, por el contrario, su propósito último estriba en impedir el ejercicio de la competencia reconocida al Estado en su decisión de establecimiento del ATC?

En base a la jurisprudencia previa del TS y partiendo de que la gestión de los residuos radioactivos es un servicio público esencial, que se reserva a la titularidad del Estado, encomendándose a la Empresa Nacional de Residuos Radioactivos S.A (ENRESA). El Acuerdo del Consejo de Ministros, de 30 de diciembre de 2011, por el que se aprobaba la designación del emplazamiento del ATC en el municipio de Villar de Cañas incide en que se reúnen las características técnicas exigidas para el emplazamiento con una calificación de MB (muy buena) en apartados como extensión y geometría, topografía, geotecnia, sismicidad, meteorología, hidrología, instalaciones de riesgo 
alrededor, zonas de interés estratégico o distancias a núcleos principales, considerando zonas no aptas las áreas descritas anteriormente. En este mismo sentido, se pronuncia el Tribunal Supremo en distintas sentencias que confirmaron la legalidad del acto, tales como la sentencia de la misma fecha 28 de octubre de 2013 al afirma que en la designación de los municipios candidatos se habían tenido en cuenta las consideraciones ambientales, señaladas por la Comisión interministerial, por las que excluían a priori, las zonas que gozasen de algún tipo de protección ambiental. Todo ello, añade la Sala Tercera, sin perjuicio del análisis singularizado de las concretas afecciones ambientales, que se deben tener en cuenta en la Declaración de Impacto Ambiental.

En síntesis, la sentencia concluye que el Estado ha venido ejerciendo legítimamente la competencia exclusiva que tenía asignada.

Por el contrario, "debemos adelantar que la actuación de la Junta de Comunidades de Castilla la Mancha se podría calificar como errática, en la medida en la que incurre en importantes contradicciones que permiten cuestionar la finalidad legítima de su proyecto de ampliación de la Laguna del Hito". Contradicciones que serán objeto de una prolija explicación:

a) Respecto a la Reserva Natural: cree el Tribunal que la primera incoherencia de la Junta de Comunidades estriba en equiparar la ampliación de la Reserva Natural a las ZEPAS/ZEC, cuando propiamente se trata de figuras distintas, como ha tenido ocasión de sentenciar el propio Tribunal Constitucional en su sentencia 234/2012, de 13 de diciembre. Especialmente porque cuando se trata de incrementar tanto una Reserva Natural como una ZEPA, desde una extensión de 1000 hectáreas hasta una superficie de 24.000 has, incrementando la protección a especies y hábitats distintos al de la grulla que motivaron la generación de la ZEPA original, la prueba de la presencia de dichos hábitats y especies susceptibles de protección, debería haber evidenciado una mayor contundencia, sobre todo teniendo en cuenta que la propia ley incluye figuras de protección más específicas. Esta ampliación desmesurada pone de relieve otras incongruencias como la inclusión de un nuevo objetivo en el Decreto consistente en el "mantenimiento y promoción de los aprovechamientos tradicionales agrícolas", no mencionado anteriormente en la tramitación, ni en la Memoria Técnica. 
b) Extensión de la ZEPA, que el Tribunal entiende todavía más incoherente basándose en decisiones previas de la Junta de Comunidades extensamente destacadas en la sentencia.De donde deducirá que, "con independencia de la valoración ambiental del proyecto del ATC que no corresponde discernir en las presentes actuaciones, la Junta de Comunidades no manifestó, en ningún momento, durante los informes exigidos en el procedimiento de evaluación ambiental, la necesidad de ampliar la ZEPA, ZEC de la Laguna de El Hito, sino que por el contrario redujo paulatinamente su extensión hasta dos meses antes de la aprobación del Acuerdo, de 28 de julio de 2015, al constatar la disminución del valor ambiental de lugar".

c) IBA 2011, que el tribunal entiende también confuso, al sustentar la Administración autonómica al sustentar la ampliación de la ZEPA en una versión de la IBA no vigente. Aunque reconoce que los IBAS no son jurídicamente vinculantes, se entiende que no se puede ignorar que se basan en criterios científicos ornitológicos equilibrados, elaborados bajo una metodología y procedimiento regulado. Ello se ha traducido en el papel clave que han adquirido para la designación de Zonas de Especial Protección para las Aves o Espacios Protegidos, pues en muchos casos los inventarios propuestos por BirdLife han sido seguidos por los Tribunales (Sentencia del Tribunal de Justicia de la Unión Europea, de 14 de enero de 2016, C141/14 sobre el incumplimiento de la Directiva Hábitats por la República de Bulgaria en lo que atañe a la IBA Kaliakra que tomó como base). Para el Tribunal Superior de Justicia de Castilla-La Mancha los inventarios IBA, por su valor científico, pueden ser utilizados " como territorios esenciales para la conservación de los grupos de aves " además de constituir la referencia más actualizada y más precisa para identificar las zonas más adecuadas, en número y en superficie, para la conservación de las aves, en defecto de otros estudios científicos que pudieran desautorizarlos y recayendo la carga de la prueba sobre el que se separe de él ( STSJ Castilla-La Mancha, de 18 de abril de 2011, rec. 262/2008, que analizaba dos Zonas de Especial Protección para las aves en el margen derecho del río Guadarrama, declaradas por Decreto 314/20017 de la Consejería de Medio Ambiente de la Junta de Comunidades). Retomando el supuesto de autos, el Acuerdo que inicia la ampliación de la ZEC/ ZEPA Laguna de EL Hitose fundamenta en la IBA 192, 
versión 1998 (extensión 23.598,06 hectáreas) y no la vigente datada en el año 2011 (21.408,49 hectáreas). Esto es especialmente indicativo, pues la superficie en la que está proyectado el almacén nuclear se incluía en la versión de 1998, pero no así en la de 2011. En la información actualizada que ofrece Seo Bird Life de la Laguna expresamente se excluyen los terrenos del ATC. Aunque enumera entre las amenazas del espacio natural, con una calificación Media, la propuesta de cementerio nuclear, frente a la Alta que se predica respecto a otros riesgos como los núcleos urbanos, o parques eólicos entre otros. Es cierto que nada impediría que se pudiera reconocer un valor ornitológico a la zona donde se proyecta el almacén nuclear, si ello se acredita mediante la prueba científica pertinente, pero esa no es para el tribunal la cuestión de fondo para abordar en este momento.

d) Exclusión de terrenos: también evidencia cierta discordancia la Junta de Comunidades al excluir del ámbito de la ampliación diversos territorios destinados a la construcción de un campo de golf y 2250 viviendas asociadas, localizados a una distancia de apenas 1 y $3 \mathrm{~km}$, frente al ATC a 10,5 km. La justificación de que dichos proyectos deberán ser sometidos, en su momento, a evaluación ambiental no parece una razón suficiente para su exclusión, desde el momento en que el almacén se encuentra exactamente en la misma tesitura.

e) Evaluación: el tribunal entiende que la protección del espacio con el reconocimiento europeo de Lugar de Importancia Comunitaria no depende exclusivamente de la existencia de una especie o hábitat determinado, sino de su representatividad en el conjunto. De aquí la necesidad de evaluación de dicho término. Es obvio que al incrementar la superficie de una ZEPA desde los 999,25 hectáreas hasta las 23.598,04 hectáreas se van a acrecentar los hábitats representados, junto con la aparición de otros nuevos. Sin embargo, lo relevante es formar una red ecológica coherente tal como se menciona en la sentencia del Tribunal de Justicia de 7 de noviembre de 2000, First Corporate Shipping, Asunto C 371/98. En este sentido, se evidencia que la representatividad de los hábitats apenas variaría con la ampliación, sin que exista prueba en contrario que desvirtúe este extremo. Sostener lo contrario, llevaría a una protección desproporcionada del territorio. 
Y como conclusión, el Tribunal sentencia que la Junta de Comunidades a través de la aprobación de los Actos impugnados trata de impedir o perturbar el ejercicio previo y legítimo de la competencia asumida por el Estado.

No es conforme con el orden de distribución de competencias que una Comunidad Autónoma pretenda introducir importantes restricciones que hagan inoperativo el ejercicio de la competencia exclusiva del Estado, y ello lo lleve hasta el extremo de conllevar la paralización de la obra proyectada, máxime cuando el Estado ha venido ejercitando dicha competencias de forma inmediata y previa, en contraposición a la Junta de Comunidades que ha actuado arbitrariamente, en el sentido de adoptar posturas claramente antípodas en un breve intervalo de tiempo.

No colma el ejercicio de la competencia del Estado, el hecho de que pueda declarar el proyecto como de interés público de primer orden, en sintonía con lo dispuesto en el artículo 19 de la Ley 42/2007, ya que haría depender el proyecto concebido primigeniamente de una decisión motivada, posterior, que podría incluso desvirtuar su contenido inicial.

Ciertamente, ello no supone que la Administración estatal cuando ejerce sus propias competencias sustanciales sobre la proyección y construcción de la obra consistente en el almacenamiento nuclear y su centro tecnológico, no deba ser respetuosa con la normativa de protección ambiental. Si la Comunidad Autónoma no estuviera, entonces, de acuerdo con la evaluación del impacto ambiental que le corresponde efectuar a la Administración estatal, podrá proceder, a interponer el recurso contencioso administrativo contra la Resolución que apruebe el proyecto, si lo considera pertinente ( artículo 41 de la Ley 21/2013).

Para terminar señalando: "lo que no cabe en ningún caso, es perseguir una finalidad subrepticia de obstrucción del ejercicio de la competencia estatal, amparándose en la apariencia de la necesidad de ampliación y conservación de espacios naturales, por muy loable que pueda resultar tal propósito". Y termina declarando la nulidad de las normas enjuciadas. 


\section{2.- AUTORIZACION AMBIENTAL INTEGRADA Y PUBLICACIÓN PREVIA DE LA DECLARACIÓN DE IMPACTO AMBIENTAL. LA POLÉMICA SOBRE LAS MACROGRANJAS PORCINAS EN EL ÁMBITO AUTONÓMICO.}

La STSJCM 10/2018 de 15 enero (RJCAl20181247) resuelve el recurso planteado por el Ayuntamiento de Torrejoncillo del Rey contra el acto presunto por silencio administrativo negativo, de la Resolución de 28 de agosto de 2014, de la Dirección General de calidad e impacto ambiental, por la que se otorga autorización ambiental integrada para una explotación porcina ubicada en un pueblo conquense y que incorpora como anexo, la declaración de impacto ambiental de las instalaciones.

La demandante había alegado un defecto sustancial que imponía al nulidad de pleno derecho de la autorización, al no seguir el procedimiento legal establecido, que impone la previa declaración de impacto ambiental y su publicidad. La Sala estima este motivo de nulidad, de carácter formal, previo a las cuestiones de derecho material y de fondo que planteaba la demanda.

Entenderá el Tribunal que es aplicable al caso la doctrina de nuestro Tribunal Supremo (Sentencia nำ1298/17, de la Sala Tercera, Sección Quinta, de 18 de julio de 2017 (RJ 2017, 3976), Sentencia de 09 de julio de 2016, recurso de casación 3539/13), que ha establecido que DIA y autorización ambiental integrada no se pueden publicar de forma conjunta, debiendo ser previa la DIA. Y ello pues así lo impone el legítimo derecho de información y participación reconocidos en materia ambiental. Además de que este orden cronológico permite una mayor garantía de valoración de los intereses ambientales concurrentes, esenciales para poder resolver sobre la procedencia de la autorización y, en su caso, las condiciones a que ha de supeditarse su otorgamiento. Esta es también la doctrina del TC (citando las Sentencias 13/98 (RTC 1998, 13) y 101/2006 (RTC 2006, 101) ), que ha entendido que tal sucesión procedimental ha de permitir ejercitar, desde una perspectiva más completa y perfeccionada, alegaciones y observaciones, que, en ningún caso, se pueden entender satisfechas en derecho, con la sola fase de información pública, que sigue a la presentación del estudio de impacto ambiental, por mucho que intervengan en ella al efecto tales interesados. Se declara así la nulidad del acto administrativo, advirtiendo que tal deficiencia procedimental no puede entenderse subsanada por la modificación no sustancial de la autorización 
ambiental integrada, publicada con posterioridad a la presentación de la demanda, pues el fondo de la cuestión, que es la mejor protección del interés ambiental, debe seguir siendo preponderante y no deja sin objeto el recurso como pretendía la Administración demandada.

Esta Sentencia cuenta con el voto particular del magistrado Miguel Angel Narvaez, que, aunque coincide en la nulidad declarada, critica como la sentencia afronta de modo preferente el motivo de nulidad por razones formales antes que el vicio por razones de fondo, cuyo examen y acogimiento debería haber sido priorizado en justa correspondencia con el suplico de la demanda planteado. Pues, a diferencia de lo que ocurre en las sentencias del Supremo donde se abordan los vicios formales de la DIA porque así se solicita, en el asunto enjuiciado esta cuestión apenas es enunciada ya en fase de conclusiones. Siendo la fundamentación y motivación del suplico de la demanda diáfana en cuanto a la solicitud de un pronunciamiento de fondo, en concreto sobre los defectos en cuanto a la insuficiencia de las medidas previstas en la DIA para preservar la pureza de las aguas y del medio ambiente.

El magistrado disidente entiende que la sentencia incurre en incongruencia con relación a la verdadera pretensión ejercitada. Y lo que es más grave, como efecto añadido deja imprejuzgada la verdadera cuestión sustantiva debatida, suficientemente acreditada por lo demás en las periciales realizadas que confirmaron la contaminación de las aguas de consumo público del Ayuntamiento de Torrejoncillo del Rey por los nitratos procedentes de los purines y estiércol originados por las granjas de cerdos y vacas de la empresa autorizada, más de 35.000 animales concentrados en los establecimientos citados. Por tanto, éste debía haber sido el motivo de nulidad del acto recurrido y no el meramente formal, "sin necesidad de esperar a un nuevo procedimiento de declaración de impacto ambiental al que la decisión de la mayoría aboca, de incierto resultado e innecesario, cuando ya se conocen los daños que se están produciendo a los afectados y las medidas paliativas, correctoras y reparadoras necesarias para evitar esos daños y riesgos son, y así se ha demostrado, deficientes e ineficaces, ante un problema de salud pública tan grave como el que padece la población del Ayuntamiento recurrente". Y que debía haber conducido indefectiblemente a la estimación del recurso. 


\section{3.- JURISPRUDENCIA EN MATERIA SANCIONADORA:}

\section{1.- Autorizaciones, interpretación y confianza legítima}

La primera decisión judicial que debemos comentar es la contenida en la STSJCM 273/2018 de 30 mayo (JUR\2018\239082), que resuelve el recurso frente la resolución del Consejero de Agricultura, MedioAmbiente y Desarrollo Rural, de 15 de diciembre de 2016, por la que se desestima el recurso de reposición interpuesto por IBERDROLA RENOVABLES ENERGÍA, S.A., contra la resolución de 18 de noviembre de 2015, del mismo órgano administrativo, por la que se resuelve el expediente sancionador que había conducido a la sanción por comisión de una infracción grave en materia de conservación de la naturaleza, tipificada en el art. 109.3 de la Ley 9/1999, de 26 de mayo de Conservación de la Naturaleza, con una multa de 85.000 euros, con la pérdida del derecho a percibir ayudas de cualquier órgano de la Junta de Comunidades de Castilla -La Mancha, para su construcción o funcionamiento durante el plazo de 1 año, así como cumplir una larga lista de medidas complementarias.

La sanción es impuesta tras la denuncia de dos agentes ambientales que comprueban que al abrirse las compuertas de la presa de Cárcavos se ha vertido, por arrastre del propio río, grava y áridos procedentes de la presa, por lo que se han colmatado las pozas naturales, y rellenado el cauce; destruyéndose parte de la vegetación acuática y de ribera, con el consiguiente daño para la fauna y para la flora.

La controversia termina siendo una cuestión fáctica sobre la interpretación y alcance de sendas autorizaciones concedidas a lberdrola para reparar grietas, revisión y limpieza en el canal, sin que se mencionara expresamente la apertura de las compuertas de la presa.

Como alegará la demandante, al explicar el orden secuencial de realización de los trabajos de limpieza y posterior reparación de grietas, es imposible la realización de los primeros sin haber garantizado previamente la estanqueidad del canal mediante idéntico mecanismo. Y que, por tanto, lo que en realidad se estaba solicitando era la autorización para la apertura de la compuerta de medio fondo de la presa durante la realización de ambos trabajos. Y lo cierto es que la Administración ni prohibió, ni limitó, ni condicionó la apertura de la compuerta. 
Sin embargo, a raíz de la pericial practica y los informes obrantes en el expediente, el tribunal entiende que lo que no aparece justificado en modo alguno es el desembalse completo de la presa, que además no se había producido hasta el momento. Como diría el abogado del Estado existía la confianza legítima en que la recurrente no aprovecharía la autorización para realizar una labor no solicitada, como era el vaciado completo de la presa para la limpieza integral del canal, mediante el vertido directo al río Mundo de todos los sólidos de sedimentación acumulados en los últimos 16 años.

Concluye por tanto el Tribunal que el vaciado completo de la presa ni estaba incluido en la solicitud, ni por tanto en la autorización, ni se ha acreditado que fuera necesario para proceder a la limpieza y reparación del canal.

No obstante, la sentencia terminará por rebajar la sanción impuesta. Y ello pues tampoco la Junta ha acreditado la existencia de daños y que la Confederación Hidrográfica ha confirmado la ausencia de los mismos, que señaló en su informe que " no ha existido afección al dominio público hidráulico ni a sus zonas de protección en ningún momento como consecuencia de las obras mencionadas ", así como que " los arrastres producidos son los típicos de un río de montaña en avenidas ordinarias ". Los informes emitidos permiten colegir, a juicio de la Sala, que la mayor parte de los daños medioambientales producidos como consecuencia del arrastre con gran fuerza, aguas abajo, de gran parte de los materiales depositados y retenidos durante años en el embalse (siendo los más aparentes gravas, arenas y sedimentos) solo son reversibles a medio o a mediolargo plazo (daños a la fauna acuática, alteración de la glanulometría por el arrastre de las gravas, colmatación de pozas existentes, procesos de turbidez de las aguas, fauna asociada al río y vegetación acuática sumergida), y que en algunos casos, como el de los cambios en la morfología de las orillas fluviales y de la vegetación existentes y la vegetación marginal de los cauces, la reversibilidad nunca será a su estado inicial.

Ahora bien, como dice la parte actora, junto a dicho informe, ha de valorarse también el emitido por la Confederación Hidrográfica, donde claramente se está indicando que el agua se desembalsó de forma progresiva; lo que vino a ser reconocido por la propia Administración. Por tanto, aun considerando acreditada la existencia de los daños aun siendo merecedores de reproche, no fueron 
superiores a los típicos de un cauce de montaña en períodos de avenidas ordinarias, lo que tiene su repercusión en la calificación de la infracción, pues el art. 109.3 de la Ley 9/1999 contempla la posibilidad de que la infracción se califique como menos grave si sus efectos son reversibles y no suponen una alteración sustancial del ecosistema.

Aplicando el principio de proporcionalidad y teniendo en cuenta el lugar donde se produjeron los hechos, Espacio Natura 2000 "Sierra de Alcaraz y Segura y Cañones del Segura y del Mundo", calificados como LIC y ZEPA (factor agravante según la letra del art. 116), y valorándose, como lo hizo la resolución sancionadora, el cumplimiento de las medidas provisionales por parte de la denunciada, resulta proporcionada la aplicación de una sanción pecuniaria, la sustitución de la sanción impuesta por otra por importe de 12.000 euros, corroborando la pérdida del derecho a percibir ayudas de cualquier órgano de la Junta de Comunidades de Castilla-La Mancha para su construcción o funcionamiento durante el plazo de 1 año y la obligación de cumplir las medidas complementarias de reparación, cuya procedencia no se ha discutido en el presente recurso contencioso-administrativo.

\section{2.- Responsabilidad por electrificación de ave en zona protegida}

La STSJCM (Sala de lo Contencioso-Administrativo, Sección 2ª̂) 251/2018 de 14 mayo (RJCAl20181892) resuelve el recurso planteado por Iberdrola frente a Resolución del Consejero De Agricultura, Medio Ambiente y Desarrollo Rural de fecha 17/08/2016, imponiendo una sanción por la comisión de una infracción muy grave en materia de conservación de la naturaleza tipificada en el artículo 108.6 de la ley 9/1999, de 26 de mayo, de Conservación de la Naturaleza (La destrucción, muerte, deterioro, recolección, captura, posesión, transporte, comercio y exposición para el comercio o naturalización no autorizados de ejemplares de animales o plantas catalogadas en peligro de extinción o sensibles a la alteración de su hábitat) con una sanción por importe de 100.001 euros así como una indemnización por importe de $64.860 €$.

Los hechos que provocan el expediente sancionador parten de la denuncia de un agente medioambiental que constata el hallazgo de un águila perdicera, a poco más de un metro de una base de apoyo eléctrico, en un paraje que tiene la 
consideración de zona de protección de la avifauna, por ser consideradas como áreas prioritarias de reproducción, alimentación, dispersión y concentración local de aquellas especies de aves incluidas en el Catálogo español de Especies Amenazadas, o en los catálogos autonómicos.

En la fundamentación jurídica, la resolución sancionadora, parte de la previsión del art. 9 de la ley 26/2007, de Responsabilidad Medioambiental, que obliga a los operadores de las actividades económicas o profesionales incluidas en la norma a adoptar y ejecutar las medidas de prevención, de evitación y de reparación de daños medioambientales. Que debe ponerse en relación con el art. 112.1 de la citada ley 9/1999, conforme al cual: 1 . Serán responsables de las infracciones administrativas previstas en esta Ley las personas físicas o jurídicas que: a) Ejecuten directamente la acción infractora, o aquéllas que ordenen dicha acción cuando el ejecutor se vea obligado a cumplir dicha orden. b) Sean titulares o promotoras de la actividad, obra, aprovechamiento o proyecto que constituya u origine la infracción. c) Estando obligadas por la presente Ley al cumplimiento de algún requisito o acción, omiten su ejecución. Resultando también de aplicación el art.3.2 del Real Decreto 1432/2008, que se aplica a las líneas eléctricas aéreas de alta tensión con conductores desnudos existentes a su entrada en vigor, ubicadas en zonas de protección, siendo obligatorias las medidas de protección contra la electrocución y voluntarias las medidas de protección contra la colisión) y, especialmente, su Disposición Transitoria Única, conforme a la cual: Los titulares de las líneas eléctricas aéreas de alta tensión a las que se refiere el art. 3.2, deberán presentar el proyecto para adaptarlas a las nuevas prescripciones técnicas. En cumplimiento del art.4.2 de este Decreto, se dictó la Resolución de 28/08/2009 por la que se delimitan las áreas prioritarias de reproducción, alimentación, dispersión y concentración local de aquellas especies de aves incluidas en el catálogo regional de especies amenazadas de Castilla-La Mancha y se dispone la publicación de las zonas de protección existentes en la Comunidad Autónoma de Castilla-La Mancha en las que serían de aplicación las medidas de protección de la avifauna contra la colisión y la electrocución en las líneas áreas de alta tensión. La zona del accidente se encuentra en el ámbito delimitado por la resolución. 
La alegación principal de la recurrente es la falta de tipicidad de la sanción, que basa en la inexistencia de responsabilidad por el hecho de que las estaciones no cumplen las prescripciones técnicas contempladas en el Real Decreto 1432/2008, entendiendo que que las modificaciones pertinentes requieren la previa financiación total por parte de la administración competente. Esta misma cuestión ya fue resuelta en la Sentencia de la misma Sala de 15 de noviembre de 2017.

Tal y como ya se decía en la resolución sancionadora, la recurrente apoya en lo previsto en la Disposición Adicional Única del Real Decreto 1432/2008 (RCL 2008, 1598), que, en sus palabras, "prevé un plan de inversiones para la adaptación de las líneas eléctricas con carácter imperativo y de mandato" y afirma que estos mecanismos financieros y presupuestarios no se han habilitado todavía. Para concluir que la instalación eléctrica fue implantada cumpliendo escrupulosamente con toda la normativa técnica y medioambiental exigible en el momento de la construcción y que no puede deducirse culpa, dolo o negligencia por su parte pues, si la administración no solicita la modificación a su costa ni habilita los presupuestos a que viene obligada, el propio artículo $112.1 \mathrm{c}$ justifica imputarle responsabilidad a la propia administración. Considera que mantener lo contrario supondría atribuir efectos retroactivos a una norma que no los contempla, afirmando que de las propias previsiones la disposición Adicional y Transitoria única resultan una serie de plazos y la obligación de fijar habilitaciones presupuestarias para hacer posible las modificaciones.

El Tribunal, haciendo suya la argumentación de la resolución sancionadora, entiende que se ha incumplido la obligación de presentar el proyecto de adaptación. Y aunque es cierto que aunque el poste 183 no estaba incluido en la resolución de 21/12/2009, el hecho de que en Agosto de 2009 se delimitaran las áreas prioritarias de reproducción, de alimentación, de dispersión y de concentración local de especies de aves incluidas en el catálogo regional de especies amenazadas de Castilla La Mancha y que en diciembre de 2010 ya se incluyera la línea dentro de las necesitadas de adaptación al Real Decreto 1432/2008, "aportando un mero presupuesto que no un verdadero proyecto de modificación determina que la demandante incurrió en la omisión negligente de una obligación prevista en la ley, por lo que al amparo del artículo 112 de la ley 
9/1999, era responsable de la infracción, una vez considerado acreditado que la muerte del águila perdicera por electrocución se produjo como consecuencia de no haberse modificado el punto de apoyo, conforme a las exigencias indicadas e impuestas normativamente".

El Tribunal entenderá que se trata de un requisito necesario, que viene impuesto a la operadora, y previo a la obtención de la financiación para la ejecución del proyecto, resultando igualmente inequívoca la obligatoriedad de las medidas de protección contra la electrocución que le impone el apartado segundo del artículo 2 del Real Decreto 1432/2008. Y que la financiación total de la adaptación se prevé como actuación posterior a la previa presentación del proyecto correspondiente, hasta el punto de que lo que se establece en esa disposición Final única y en el apartado segundo de la Disposición Transitoria Única es que lo que va a depender de la disponibilidad de la financiación no es la obligación de presentar el proyecto sino la ejecución del mismo.

No habiéndose presentado oportunamente el proyecto ni siquiera puede entrar a valorarse el alcance y la forma que podía hacerse efectiva esa financiación programada ni tampoco un eventual incumplimiento y el alcance del mismo a efectos de excluir la responsabilidad de la operadora y trasladarla a la administración a la que, según la norma, corresponde tal financiación.

No se trata de aplicación retroactiva de las normas sino de cumplir las obligaciones que le vienen impuestas más allá de mantener las líneas eléctricas en el mismo estado en el que se implantaron; pues, como indica la propia resolución sancionadora recurrida, viene obligado por art.9 L 26/2009 a adoptar y a ejecutar las medidas de prevención, de evitación y de reparación de daños medioambientales y a sufragrar sus costes. El Tribunal terminará confirmando la legalidad de la sanción impuesta.

\section{4.- JURISPRUDENCIA CONSTITUCIONAL Y FRACKING: LA CONSTITUCIONALIDAD DE LA LEY CASTELLANO-MANCHEGA}

Si bien no se trata de una sentencia dictada en nuestro ámbito territorial, me ha parecido interesante dar cuenta de la STC (Pleno) 65/2018, de 7 de junio (RTC/2018/65), en el recurso de inconstitucionalidad promovido por el Presidente del Gobierno contra el artículo 3 y las disposiciones transitorias 
primera y segunda y disposición final primera de la Ley de las Cortes de CastillaLa Mancha 1/2017, de 9 de marzo, por la que se establecen medidas adicionales de protección de la salud pública y del medio ambiente para la exploración, investigación o explotación de hidrocarburos utilizando la técnica de la fractura hidráulica, de la que ya se dio cuenta en estas mismas crónicas ${ }^{1}$. Y nos parece apropiado porque, como analizaremos, frente a una doctrina constitucional previa, esta sentencia es la primera que avalará la constitucionalidad de una ley autonómica sobre el fracking, pues nuestro legislador, seguramente consciente de aquella doctrina consolidada, cuidó bien el despliegue de competencias y los límites que normativa y jurisprudencialmente tenía como antecedentes.

Como bien señala el TC, este recurso es fundamentalmente competencial: el Abogado del Estado considera que los preceptos impugnados incurren en inconstitucionalidad "mediata" por vulneración de los títulos competenciales estatales de los núms. 13 (bases y coordinación general de la planificación económica), 23 (normas básicas de protección del medio ambiente) y 25 (bases del régimen minero y energético) del artículo 149.1 CE.

Haciendo un breve repaso histórico, la decisión se enmarca en una serie derivada de la aprobación de la Ley estatal 17/2013, de 29 de octubre, del artículo 9.5 de la Ley 34/1998, de 7 de octubre, del Sector de Hidrocarburos, que autoriza el empleo de la técnica de la fractura hidráulica o fracking, y de sucesivas leyes autonómicas prohibiendo o restringiendo de algún modo el empleo de esta técnica. La normativa estatal reguladora del fracking se completa con la Ley de 9 de diciembre, de evaluación ambiental, que prevé que los riesgos que esta actividad puede generar para el medio ambiente deben valorarse caso por caso por el "órgano ambiental" de cada Administración (estatal o autonómica) según cuál de ellas sea la competente para otorgar el título habilitante (autorización de exploración, permiso de investigación o concesión de explotación, en la sistemática de la Ley del sector de hidrocarburos) requerido por el proyecto que prevea el empleo de la técnica de la fractura hidráulica, a través de la correspondiente "evaluación de impacto ambiental".

\footnotetext{
${ }^{1}$ En el recurso de inconstitucionalidad, se solicitó la suspensión de la vigencia de la norma autonómica, que fue acordada mediante Providencia de 23 de enero de 2018 (BOE, de 31 de enero).
} 
El distinto entendimiento de este corpus normativo, estatal y autonómico ha dado lugar a una jurisprudencia constitucional en las SSTC 106/2014, de 24 de junio, 134/2014, de 22 de julio, 208/2014, de 15 de diciembre, 73/2016, de 14 de abril, y 8/2018, de 25 de enero. En todas ellas las normas autonómicas fueron corregidas por extralimitación competencial, entendiendo el art.9.5 LHS como una determinación básica del Estado amparada en los títulos competenciales de los núms. 13 ("bases y coordinación de la planificación general de la actividad económica") y 25 ("bases del régimen... energético") del artículo 149.1 de la Constitución. Así, las SSTC 106/2014, 134/2014, y 208/2014, declararon inconstitucionales y nulas las leyes de las Comunidades Autónomas de Cantabria, La Rioja y Navarra, respectivamente, que contenían una "prohibición absoluta e incondicionada" de la técnica de la fractura hidráulica en sus territorios. Y la STC 73/2016 hizo lo propio con una modificación de la Ley de urbanismo de Cataluña que, sin contener una prohibición semejante, producía sin embargo un efecto equivalente. La STC 8/2018, declaró inconstitucional y nula la modificación de la Ley del suelo y urbanismo del País Vasco, cuya redacción era prácticamente idéntica a la catalana. Sin embargo, la misma sentencia declaró ajustada a la legalidad la norma que prohibía el uso de la técnica "en aquellos espacios clasificados como de riesgo de vulnerabilidad media, alta o muy alta en el mapa de vulnerabilidad a la contaminación de los acuíferos de la Comunidad Autónomas vasca." La fundamentación jurídica de esta decisión se basó en una amplia interpretación de la norma competencial del art.149.1.23 CE en la materia de "protección del medio ambiente", donde las Comunidades Autónomas pueden aprobar "normas adicionales de protección" a las básicas aprobadas por el Estado. Y así se señaló por el TC que la norma recurrida: (i) no contravenía las normas básicas sobre protección del medio ambiente aprobadas por el propio Estado para prevenir la contaminación de acuíferos, con cita en concreto del artículo 129 de la Ley 62/2003, de 30 de diciembre, de medidas fiscales, administrativas y del orden social, y del Real Decreto 1514/2009, de 2 de octubre, por el que se regula la protección de las aguas subterráneas contra la contaminación y el deterioro; (ii) y además podía acomodarse a la normativa básica económica y energética que representa el antes citado artículo 9.5 LSH de acuerdo con la doctrina anterior del Tribunal conforme a la cual en desarrollo de estas bases las Comunidades Autónomas 
"pueden imponer deberes y cargas para el otorgamiento de autorizaciones, permisos y concesiones mineras con la finalidad de proteger el medio ambiente, siempre que las mismas sean razonables y proporcionadas al fin propuesto y no alteren el ordenamiento básico en materia de régimen minero y energético" [STC 8/2018, FJ 4 b)]. El Tribunal tomó especialmente en consideración para llegar a esta conclusión: (i) que la prohibición afectaba a una superficie que representaba "el treinta y siete por ciento del territorio" de la Comunidad Autónoma; (ii) que la prohibición había venido precedida de una "previa evaluación de cada uno de los acuíferos" del País Vasco; (iii) que solo afectaba a los acuíferos "de vulnerabilidad media, alta o muy alta de contaminación", y no a los de vulnerabilidad "baja o muy baja"; (iv) y finalmente que "la prohibición autonómica recurrida tiende a proteger un recurso esencial del medio ambiente, el agua, cuyas características pueden hacer que se multipliquen exponencialmente y sean irreversibles los efectos contaminantes que, no habiéndose previsto en la evaluación de impacto ambiental, incluso por insuficiencia de los conocimientos técnicos, pudieran no obstante producirse. El agua es un recurso 'unitario' e integrante de un mismo ciclo (art. 1.3 del texto refundido de la Ley de aguas y STC 227/1988, de 29 de noviembre, FJ 14) y es además un recurso 'vital' (STC 102/1995, de 26 de junio, FJ 6) con una influencia decisiva sobre la vida humana, animal y vegetal. Por todo ello, la prohibición autonómica no puede considerarse irrazonable ni desproporcionada" (ibidem).

Siendo estos los hitos fundamentales de la jurisprudencia constitucional recaída en esta serie sobre el fracking, la STC sobre nuestra Ley autonómica será bien diferente.

El recurso se dirige principalmente contra el artículo de la ley autonómica que regula el "plan estratégico de la utilización de la fractura hidráulica" que debe ser elaborado por la Consejería competente en materia de medio ambiente, en colaboración con las competentes en materia de salud pública, energía y ordenación del territorio, y deberá ser aprobado por el Consejo de Gobierno en el plazo máximo de dieciocho meses. Este Plan debe efectuar una "evaluación de riesgos a escala regional" y proceder a una "zonificación del territorio" de toda la Comunidad Autónoma a fin de diferenciar zonas "aptas para la aplicación de la fractura hidráulica", zonas donde esta técnica quede "restringida", "zonas de 
exclusión" y "distancias mínimas de protección". Y para efectuar esta tarea proporciona a la Administración una serie de criterios: debe guiarse por la "protección a la salud humana y la biodiversidad", atendiendo a "los riesgos" de la técnica del fracking "para la contaminación de las aguas superficiales y subterráneas, por la naturaleza de la potencial sismicidad inducida, para evitar afecciones sobre las áreas y recursos naturales protegidos, para evitar impactos sobre el patrimonio cultural, así como por una afección relevante sobre el resto de elementos geológicos, ambientales, paisajísticos o socioeconómicos”.

Y justamente aquí es donde encontramos la principal diferencia con las leyes autonómicas enjuiciadas hasta la fecha por el Tribunal. Puesto que, como bien señala el FJ 4 de la Sentencia: $\left.1^{\circ}\right)$ ni contiene una prohibición legal expresa de esta técnica de carácter absoluto e incondicionado como en los casos de las SSTC 106/2014, 134/2014, y 208/2014.

2º) Ni efectúa una remisión incondicionada o en blanco a la Administración para que regule su posible uso (reformas de las leyes del suelo de Cataluña y País Vasco declaradas inconstitucionales en las SSTC 73/2016 y 8/2018).

$3^{\text {o) }} \mathrm{Ni}$ tampoco contiene una medida singular en relación con determinados acuíferos como en el caso de la reforma de la Ley de aguas del País Vasco declarada constitucional.

Efectivamente, este precepto contiene "una norma novedosa y no examinada hasta la fecha, consistente en habilitar a la Administración autonómica para que esta efectúe una "zonificación" del territorio de la Comunidad Autónoma y delimite áreas donde la técnica del fracking quede excluida, restringida o permitida en atención a los criterios que la ley señala y que, a diferencia de lo acontecido en las reformas de las leyes del suelo de Cataluña y País Vasco anuladas en las antes aludidas SSTC 73/2016 y 8/2018, no incluyen una referencia final a cualquier ámbito competencial de la Comunidad Autónoma". Sin que, frente a lo reclamado por la representación estatal, quepa anticipar ni hacer hipótesis sobre los resultados de esa zonificación que se encomienda a la Administración, ni dictar pronunciamientos preventivos para evitar una posible y no producida aplicación del precepto en contradicción con la Constitución. 
EI TC analizará seguidamente el encuadramiento competencial del precepto en discusión, que se centra en las competencias autonómicas de desarrollo de las bases estatales en materia de protección del medio ambiente y ordenación del territorio. Descartando otras, especialmente la de protección y prevención de la salud (fuertemente defendida por el legislador autonómico), que considera instrumental al título prevalente y más específico de protección ambiental.

La íntima relación entre ambos títulos competenciales (ordenación del territorio y medio ambiente) ya ha sido destacada por la doctrina constitucional, por ejemplo en la STC 306/2000, de 12 de diciembre, FJ 7, sobre sobre el plan de ordenación de los recursos naturales de Picos de Europa). Lo relevante es que desde uno u otro título -ordenación del territorio, competencia exclusiva, o medio ambiente, competencia de desarrollo de las bases estatales y de ejecución - la Comunidad Autónoma puede crear un instrumento normativo como el "plan estratégico de la utilización de la fractura hidráulica" de este artículo 3.

Y la sentencia declara que resulta indiscutible desde la perspectiva de la ordenación del territorio, pues la competencia de las Comunidades Autónomas "para crear instrumentos de planeamiento distintos de los enunciados en la legislación estatal" que aquellas "considere[n] adecuados para llevar a cabo dicha ordenación" (STC 36/1994, FJ 6, entre otras muchas). Por lo que respecta a la competencia sobre medio ambiente, el Estado puede dictar al amparo del artículo 149.1.23 CE normas básicas sobre la planificación de los recursos naturales, pero no impone necesariamente que esta sea la única planificación existente, pues deja abierta la posibilidad de que las Comunidades Autónomas puedan establecer otros instrumentos con el mismo fin de protección medioambiental, tan claro como lo señala el 17.1 de la Ley 42/2007, de 13 de diciembre, de Patrimonio Natural y la Biodiversidad ("Los Planes de Ordenación de los Recursos Naturales son el instrumento específico para la delimitación, tipificación, integración en red y determinación de su relación con el resto del territorio, de los sistemas que integran patrimonio y los recursos naturales de un determinado ámbito espacial, con independencia de otros instrumentos que pueda establecer la legislación autonómica. Su vigencia y plazos de revisión 
serán definidos por la normativa de las comunidades autónomas o, en el ámbito de sus competencias, por la Administración General del Estado.").

De todo ello infiere el TC que la regulación por la Comunidad Autónoma de Castilla-La Mancha del "plan estratégico de la utilización de la fractura hidráulica" efectuada en el artículo 3 de la Ley 1/2017 responde a un legítimo ejercicio de sus competencias. Sin que quepa prejuzgar el desarrollo posterior que la administración autonómica haga de aquella competencia.

Y concluye lo mismo desde la perspectiva de la ordenación del territorio: la posibilidad de que las Comunidades Autónomas incidan en el ejercicio de las competencias sectoriales del Estado, como es en este caso la competencia para otorgar determinados permisos, autorizaciones y concesiones de acuerdo con los artículos 14, 15 y 25 de la Ley del sector de hidrocarburos (también amparada por la jurisprudencia constitucional). Aunque también se haya considerado necesario coordinar las competencias concurrentes y de que las Comunidades Autónomas respeten el legítimo ejercicio por el Estado de sus competencias sectoriales si éste las ejercita "dentro de los límites propios": "La multiplicidad de actuaciones que inciden en el territorio requiere la necesidad de articular mecanismos de coordinación y cooperación, pero no su incorporación automática a la competencia de ordenación del territorio, de manera que el competente en esta materia, al ejercer su actividad ordenadora, estableciendo los instrumentos de ordenación territorial, deberá respetar las competencias ajenas que tienen repercusión sobre el territorio coordinándolas y armonizándolas desde el punto de vista de su proyección territorial [SSTC 149/1991, FJ 1 B), y 36/1994, FJ 3]." Esto es, la actividad de planificación de los usos del suelo, así como la aprobación de los planes, instrumentos y normas de ordenación territorial se insertan en el ámbito material de la competencia sobre ordenación del territorio, cuyo titular deberá ejercerla sin menoscabar los ámbitos de las competencias reservadas al Estado ex art. 149.1 CE que afecten al territorio teniendo en cuenta los actos realizados en su ejercicio y respetando los condicionamientos que se deriven de los mismos (STC 36/1994, FJ 2).

Por ello, concluirá el TC aplicando esta doctrina al caso de autos que: "no procede evaluar aquí la adecuación del plan aun no aprobado ni objeto de este proceso...Procede en cambio declarar, de acuerdo con todo lo anterior, que la 
simple previsión de un "plan estratégico de la utilización de la fractura hidráulica" que debe aprobar el Gobierno autonómico contenida en el artículo 3 de la Ley de Castilla-La Mancha 1/2017, no puede considerarse contraria al orden constitucional de distribución de competencias.

Siendo esta la sentencia determinante sobre la constitucionalidad de la norma castellano-manchega, el TC también examinará la DT primera por su condición instrumental o accesoria respecto del artículo 3, que establece lo siguiente: "No se concederán nuevas autorizaciones de exploración, permisos de investigación ni concesiones de explotación de hidrocarburos obtenidos a través de fractura hidráulica en tanto no se apruebe el plan estratégico sectorial al que hace referencia el artículo tres" Y que el Estado entiende que produce el efecto "real" de una prohibición absoluta e incondicionada "aunque esté sujeta a término".

Sin embargo, entenderá el TC que es precisamente ese carácter temporal de la prohibición el que impide asignar a esta un significado y efecto equivalente al de las prohibiciones absolutas e incondicionadas no sujetas a término examinadas en las Sentencias constitucionales anteriores: "El alcance temporal de la prohibición, por un plazo razonable (visto el contenido del plan y los trámites previstos en el propio artículo 3) y cierto (pues expira a los dieciocho meses en que según el propio artículo 3 debe procederse a la aprobación de ese plan por el Gobierno autonómico), hacen de esta norma un ejercicio legítimo, razonable y proporcionado de las competencias autonómicas. Su propósito no es otro que salvaguardar los objetivos que justificaron la regulación del plan estratégico sectorial del artículo 3 por el tiempo indispensable para su aprobación". Por tanto, también supone un ejercicio legítimo de las competencias autonómicas y es razonable y proporcionada al fin propuesto.

Más relevante es el juicio de constitucionalidad, de marcado carácter interpretativo de la también recurrida disposición final primera de la Ley 1/2017, que introduce un nuevo apartado c) en el artículo 54.1.3 del Decreto Legislativo 1/2010, de 18 de mayo, por el que se aprueba el texto refundido de la Ley de ordenación del territorio y de la actividad urbanística, sobre el régimen del suelo rústico, permitiendo las siguientes actividades, previa obtención de la preceptiva calificación urbanística y siempre que la ordenación urbanística y territorial no los prohíba: “c) Los proyectos consistentes en la realización de perforaciones 
para la exploración, investigación o explotación de hidrocarburos, almacenamiento de $\mathrm{CO} 2$, almacenamiento de gas y geotermia de media y alta entalpía, que requieran la utilización de técnicas de fracturación hidráulica."

Por lo tanto, el sentido de la reforma es habilitar a la "ordenación territorial y urbanística" para que pueda "regular" la técnica de la fractura hidráulica en todo el suelo clasificado como suelo rural "de reserva" (que es el suelo que no tiene un régimen de especial protección por los especiales valores en ellos concurrentes -medioambientales, hidrológicos, agrícolas, forestales, etcéterao por la protección del dominio público); una prohibición que, de aprobarse, impediría incluso una posterior calificación que legitime ese uso singular, pues la calificación urbanística del suelo de reserva para la legitimación de obras, construcciones o instalaciones destinadas a actividades o usos prohibidos solamente se permite "siempre que la ordenación urbanística y territorial no los prohíba”, de acuerdo con el artículo 54.1.3 en que se inserta el apartado c) objeto de recurso.

Sobre esta cuestión, y según los precedentes constitucionales sobre la cuestión, el Tribunal recuerda que son contrarios a la Constitución mandatos autonómicos que "reformula[n]" las bases estatales de modo que "reducen, dificultan o impiden la eficacia" del artículo 9.5 LSH (STC 73/2016, FJ 9, refiriéndose a la modificación de la Ley de urbanismo de Cataluña sobre la prohibición del fracking en el suelo no urbanizable de la Comunidad). Como lo son las remisiones incondicionadas o en blanco a los instrumentos de ordenación territorial y urbanística que permiten llegar al mismo resultado [STC 8/2018, FJ 4 a), sobre la modificación de la Ley del suelo de País Vasco), aunque teniendo siempre presente que "la razón determinante" para apreciar la inconstitucionalidad de estas habilitaciones reglamentarias no es esa remisión o habilitación en sí, sino "la falta de determinación precisa de requisitos razonables y proporcionados al fin de protección medioambiental, o en otros términos, la indeterminación de los criterios enunciados en la norma (STC 73/2016, FJ 9)"

En conclusión, "si la norma impugnada hubiera de entenderse como una remisión en blanco o incondicionada a los instrumentos de ordenación territorial o urbanística para que cualquiera de esos instrumentos pudiera prohibir de manera autónoma o aislada la técnica de la fractura hidráulica en su ámbito 
territorial, haciéndolo además sin sujeción a criterio alguno en la medida en que la norma omite cualquier referencia a ellos, dicha remisión habría de ser declarada inconstitucional en aplicación de la jurisprudencia reseñada [SSTC 73/2016, FJ 9, y 8/2018, FJ 4 a)]. No obstante, una interpretación sistemática de esta modificación legislativa, "en relación con el contexto" de la Ley 1/2017 en que se integra (art. 3.1 del Código civil), permite otorgar a esta disposición final primera otra interpretación, y entender que la habilitación contenida en el artículo $54.1 .3 \mathrm{c}$ ) de la Ley de ordenación territorial y actividad urbanística de Castilla-La Mancha no se efectúa en esos términos tan amplios y abiertos, llamando a cualquier planificador de manera indistinta, sino que debe colmarse y ejercerse siempre en o a través del "plan estratégico de la utilización de la fractura hidráulica" regulado en el artículo 3 de la Ley 1/2017, que ya hemos declarado conforme con el orden constitucional de distribución de competencias. Por lo tanto, siendo ese artículo 3 conforme con la Constitución, esta misma conclusión debe hacerse extensiva a la disposición final primera de la Ley $1 / 2017$ si se entiende, de acuerdo con la interpretación sistemática indicada, que será en el referido "plan estratégico de la utilización de la fractura hidráulica", o, en su caso, en otros instrumentos de ordenación del territorio pero siempre con amparo y cobertura en las previsiones del primero, donde podrán establecerse y precisarse las limitaciones y eventuales prohibiciones a proyectos que requieran la utilización de la fractura hidráulica"

Por tanto, habrá que esperar a lo que la regulación autonómica sobre "el plan estratégico de la utilización de la fractura hidráulica" establezca. Resultando, hasta que llegue ese momento, impecable desde el punto de vista de la distribución constitucional la norma autonómica sobre el uso de la técnica de la fractura hidráulica².

\footnotetext{
${ }^{2}$ La cuestión, ampliamente debatida, ha sido objeto de numerosos estudios doctrinales, remitiéndonos en esta crónica a uno de los últimos aparecidos, muy crítico con las regulaciones autonómicas, y a la bibliografía en él citada: FERNANDEZ DE GATTA, D., "De nuevo (iiy van...6!!) Leyes antifracking ante el TC", Diario La Ley n"9161, edición de 19 de marzo de 2018).
} 